\title{
Publisher's Note: High intensity ion beams in rf undulator linac [Phys. Rev. ST Accel. Beams 11, 074201 (2008)]
}

\author{
E. S. Masunov and S. M. Polozov
}

(Received 14 July 2008; published 22 July 2008)

DOI: 10.1103/PhysRevSTAB.11.079901

PACS numbers: 29.20.Ej, 29.27.Bd, 99.10.Fg

This paper was published online on 10 July 2008 with composition errors in the $U_{1}$ and $U_{2}$ equations on page 2, righthand column. The paper has been corrected as of 14 July 2008. 